(C) Dereito Vol.27, nºEXT:137-159 (Xaneiro-Decembro, 2018) • ISSN 1132-9947

\title{
TRANSPARENCIA, BUEN GOBIERNO Y DERECHO DE ACCESO A LA INFORMACIÓN PÚBLICA
}

Transparency, good governance and the right of access to public information

DOI: http://dx.doi.org/10.15304/dereito.27.Ext.5788

Ana María Aba Catoira

Profesora Titular de Derecho Constitucional

Universidade de A Coruña

ana.abac@udc.es

\section{Resumen}

La publicidad tiene un efecto de legitimización y democratización del sistema, pues permite mantener a la ciudanía informada sobre los asuntos públicos para participar con libertad y responsabilidad y, en consecuencia, exigir rendición de cuentas a los cargos públicos.

Estos objetivos de alto valor democrático obligan dentro de la cultura de transparencia a que los poderes públicos asuman obligaciones que los vinculen más allá de los principios de actuación. De ahí que la transparencia requiera unas obligaciones concretas y la regulación garantista de un derecho de acceso a la ciudadanía que le faculte para solicitar más informaciones que aquellas que responden al cumpliendo el principio de publicidad activa. Abordaremos los aspectos del derecho de acceso en la regulación dada por la ley estatal y en la LGT, poniendo el acento en los déficits y proponiendo soluciones.

Palabras clave: Transparencia, Buen Gobierno, Gestión Pública, Derecho de acceso, Información pública, Libertades de Información.

\section{Abstract}

The publicity has an effect of legitimization and democratization of the system, because it allows to keep the citizenship informed about public matters in order to participate with freedom and responsibility and, consequently, to demand accountability to public offices. These objectives of high democratic value require within the culture of transparency that public powers assume obligations that link them beyond the principles of action. Hence, transparency requires specific obligations and the guarantee regulation of a right of access to citizenship that entitles it to request more information than those that respond by complying with the principle of active publicity. We will address the aspects of the right of access in the regulation given by the state law and in the LGT, putting the accent on the deficits and proposing solutions.

Keywords: Transparency, Good Government, Public Management, Right of access, Public information, Freedom of Information.

Recibido: 10/12/2017. Aceptado: 09/09/2018. 


\section{SUMARIO}

1. PRESENTACIÓN.;- 2. DERECHO DE ACCESO A LA INFORMACIÓN PÚBLICA: 2.1. Derecho de acceso y políticas públicas de transparencia. 2.2. Reconocimiento del derecho de acceso y su desarrollo normativo.;- 3. EL DERECHO DE ACCESO EN LA LEY GALLEGA.;- 3.1. Concepto del derecho de acceso.;- 3.2. Aspectos sustantivos: concepto de información pública, titularidad y limitaciones.;- 3.3. Aspectos procedimentales.;- 4. BIBLIOGRAFIA.

\section{PRESENTACIÓN}

En los inicios de la Sociedad de la Información o Sociedad del Conocimiento el término Gobierno Electrónico venía a significar que las relaciones entre administración y administrados se realizaban a través de los canales tecnológicos que agilizaban la gestión y tramitación administrativas $\mathrm{y}$, por consiguiente, se convertían en un activo para la eficacia y eficiencia en la función pública ${ }^{1}$. Fue en 2009 , primero durante la campaña a la Presidencia del candidato Obama y después una vez proclamado Presidente, cuando el término "Gobierno Abierto" adquirió protagonismo. Se aprobó la Open Government Directive un instrumento de gobierno que recoge su compromiso de restablecer la confianza ciudadana en los poderes públicos haciendo de la transparencia, la colaboración y la participación objetivos de primer orden para fortalecer la democracia y alcanzar la eficacia del gobierno. En Europa supusieron importantes avances, la "Declaración Ministerial sobre administración electrónica", aprobada por unanimidad en Malmö ${ }^{2}$ y la Recomendación del Comité de Ministros del Consejo de Europa a los Estados miembros sobre la democracia electrónica.

El Gobierno Abierto llega gracias a la web 2.0 y supone la implantación de cambios organizativos para mejorar los servicios públicos y los procesos de toma de decisiones, para lo que se implantan principios de transparencia como la publicidad de la actuación y gestión pública, garantizando un acceso libre y gratuito a las informaciones públicas a través de la publicidad activa o del ejercicio del derecho de acceso o publicidad pasiva. La disponibilidad de los datos en abierto en formatos fácilmente accesibles y con carácter gratuito para que la ciudadanía pueda participar en lo público y colaborar con los poderes del Estado en buena medida a través de la reutilización de esos datos que permiten crecer social y económicamente además de mejorar la gestión. Por tanto, el cambio en el sistema tradicional se realiza a partir de tres pilares: la transparencia en las actuaciones y procedimientos, la colaboración dentro del gobierno y del gobierno con la ciudadanía para una mejor resolución

\footnotetext{
${ }^{1}$ J. J. FERNANDEZ RODRIGUEZ: "La aprehensión jurídica de la democracia y el gobierno electrónicos", en L. Cotino Hueso (coord.), Libertades, democracia y gobierno electrónico, Comares, Granada, 2006.

${ }^{2}$ Aprobada el 18 de noviembre de 2009.
} 
de los problemas sociales y la participación de la ciudadanía en el diseño y ejecución de las políticas ${ }^{3}$.

Este nuevo modelo de gestión se identifica con una demanda ciudadana de suministro de canales de información que satisfagan el derecho a saber, a obtener información, y es una exigencia democrática que se traduce en una nueva forma de trabajar y de gestionar lo público, siendo constante la medición, la autoevaluación o las propuestas de mejora, que deben redundar no solo en un incremento de la interactuación de la ciudadanía con la administración sino también en una mayor calidad de la gestión pública 4 .

En este orden de cosas y como no puede ser de otro modo, en la Constitución Española de 1978 se reconocen las libertades de expresión e información, el derecho de acceso a la información pública y el derecho a participar en los asuntos públicos como pilares del Estado democrático que fundamentan la apertura de los nuevos modelos de gestionar lo público. Posteriormente, y en distintas etapas, los Estados han ido legislando y dotando de regulación al derecho de acceso siendo destacable que en nuestro ordenamiento carece de rango fundamental y hasta la Ley estatal 19/2013, de 9 de diciembre, de Transparencia, Acceso a la información pública y Buen gobierno, carecía de una regulación autónoma.

\section{DERECHO DE ACCESO A LA INFORMACION PÚBLICA}

\subsection{Derecho de acceso y políticas públicas de transparencia}

El Gobierno abierto es un modelo transparente en el cual la ciudadanía copropietaria de lo público tiene reconocido un derecho a saber o conocer como presupuesto para formarse una opinión libre, para una participación responsable y para poder controlar permanentemente la gestión pública que es la gestión del interés general. Así, la publicidad y transparencia informativa se convierten en principios de actuación en el ámbito público y la reserva o secreto en la excepción.

Las políticas de transparencia son, en definitiva, políticas públicas que encarnan principios específicos, valores y derechos (Buena Administración, art. 41 CDFUE) ${ }^{5}$ necesarios para gestionar los asuntos públicos y para garantizar el acceso a la información que generan reformas legislativas necesarias para esta redefinición de la actuación de los poderes públicos que asumen nuevas exigencias que afectan a principios clásicos como los de eficacia, eficiencia y calidad administrativa. Estos principios básicos

3 El paradigma del Gobierno Abierto. Retos y oportunidades de participación y colaboración, L. COTINO, J. L. SAHUQUILLO y L. CORREDOIRA (eds.), Universidad Complutense de Madrid, 2015.

4 En este sentido, Comunicación 1 COM (2003), 567, "El papel de la Administración Electrónica en el futuro de Europa", Bruselas, 26 de septiembre de 2003.

${ }^{5}$ El Buen Gobierno que ha sido definido por la Comisión Europea como "el que representa generalmente el ejercicio del poder político, económico y administrativo en el marco de la gestión de los asuntos de un país [...] se referirá a una gestión pública transparente, responsable, participativa, equitativa y respetuosa de los derechos fundamentales", COM (1998), 146 final 9 y que se consagró, por primera vez, como un derecho de la ciudadanía en la Carta de Derechos Fundamentales de la Unión Europea proclamada en la Cumbre de Niza de diciembre 2000. 
consagrados en la Constitución adquieren un nuevo significado desde el parámetro de la transparencia pues para su efectividad habrán de aumentar la participación y la colaboración ciudadana a través del derecho de acceso a las informaciones públicas ${ }^{6}$.

En la literatura científica se han distinguido dos tipos de políticas de transparencia que dependen del nivel de desarrollo, así están las de primera generación y las de segunda generación. En las primeras el control es vertical ya que, gracias al acceso a la información pública, la ciudadanía puede controlar la gestión pública. En las segundas, la información obtenida no se gestiona por la ciudadanía para exigir responsabilidades sino por empresas u organizaciones privadas para denunciar ante la opinión pública la mala gestión pública en un ámbito específico ${ }^{7}$.

Así lo anterior, el reconocimiento y desarrollo legal de este derecho de acceso a las informaciones públicas se producen en las democracias occidentales en el marco de las políticas públicas de transparencia ${ }^{8}$.

En nuestro Derecho la LETAI y la LGT recogen este objetivo en sus respectivas exposiciones de motivos, "solo cuando la acción de los responsables públicos se somete a escrutinio, cuando los ciudadanos pueden conocer como se toman las decisiones que les afectan, como se maneja el dinero público o bajo qué criterios actúan nuestras instituciones podremos hablar de una sociedad crítica, exigente y participativa"; "La importancia del control ciudadano sobre la actividad gubernamental en una democracia queda acreditada desde los debates que precedieron a la promulgación de la primera constitución democrática de la historia. En los llamados «papeles federalistas», pensadores como James Madison o Alexander Hamilton introducían los conceptos de «rendición de cuentas» o «controles y contrapesos» como elementos esenciales que se encuentran en la raíz de la democracia".

Dicho lo cual comprobamos como el derecho de acceso a la información pública es una proyección del principio democrático de transparencia o publicidad que está generalizado en todas las constituciones. En nuestro ordenamiento nacional el principio de transparencia como tal no aparece expresamente en la Constitución si bien la publicidad es un principio transversal que rige todas las actuaciones públicas, del poder legislativo,

\footnotetext{
${ }^{6}$ Véase mi trabajo A. ABA CATOIRA: "La participación ciudadana en la administración de justicia a través del acceso a la información pública" en El paradigma del Gobierno Abierto. Retos y Oportunidades de participación y colaboración, L. COTINO, J. L. SAHUQUILLO y L. CORREDOIRA (eds.), Universidad Complutense de Madrid, 2015.

7 R. ACKERMAN: Corruption and Government: Causes, Consequences and Reform, Cambridge, Cambridge University Press.

${ }^{8}$ La bibliografía es extensa pero por completa y de reciente publicación nos remitimos a M. FERNANDEZ SALMERON y J. VALERO TORRIJOS (coords), Régimen jurídico de la transparencia en el sector público: acceso, uso y reutilización de la información administrativa, Thomson-Aranzadi, Madrid, 2014; E. GUICHOT REINA (coord.), Transparencia, Acceso a la Información Pública y Buen Gobierno, Tecnos, Madrid, 2014. Puede consultarse el XIII Informe sobre Derechos Humanos "Transparencia e Información Pública", G. ESCOBAR (dir.), Federación Iberoamericana de Ombudsman, Trama Editorial, Madrid, 2015.
} 
del poder ejecutivo y del poder judicial. Así, podemos ubicar su fundamento en varios preceptos. En cuanto al poder legislativo, tenemos que referirnos al art. 9.30 que establece el principio de publicidad de las normas o al art. $120.3^{\circ}$ sobre publicidad de las sesiones plenarias de ambas Cámaras; respecto al poder judicial, el derecho a un proceso público integrado en el derecho fundamental a la tutela judicial efectiva del art. $24.2^{\circ}$ y la publicidad del proceso y de las resoluciones judiciales del art. $120.1^{\circ}$. No cabe olvidar que la publicidad desde una perspectiva individual como derecho a saber o mantenerse informado, se hace patente en varios derechos fundamentales art. $18.4^{\circ}$ que reconoce el derecho de autodeterminación informativa; el art. 20 donde se garantizan las libertades de expresión e información y en el art.105.b) que contiene un derecho constitucional no fundamental ${ }^{9}$ que obliga al legislador a configurar este derecho, su contenido, alcance y régimen de ejercicio.

\subsection{Reconocimiento del derecho de acceso y su desarrollo normativo}

Por lo que se refiere a la evolución normativa de este derecho diremos que los países nórdicos y los Estados Unidos de Norteamérica fueron los primeros en aprobar leyes de regulación del derecho de acceso a la información pública, generalizándose a finales del siglo XX en la Europa occidental no a través de leyes de acceso a la información sino en regulaciones insertadas en leyes de naturaleza administrativa. Son ya del siglo XXI las leyes de transparencia, buen gobierno y acceso a la información, siendo ejemplo de ello la ley estatal española o las leyes autonómicas, sobre las que podríamos decir que hacen una regulación de la transparencia desde el Derecho administrativo y no desde una perspectiva constitucional, priorizando el acceso sin el cual no puede haber transparencia. Su aprobación se produce en un contexto social y político caracterizado por la desafección de la sociedad hacia lo público en buena medida por falta de transparencia y el elevado número de casos de corrupción.

Los orígenes podemos situarlos en la Declaración Francesa de Derechos del Hombre y del Ciudadano de 1789 en cuyo art. 15 se proclama que "la sociedad tiene derecho a exigir a todo agente público que le rinda cuentas de su administración". Históricamente se reconoce dentro del ámbito de las libertades de expresión e información como una facultad comprendida en las mismas sin un reconocimiento autónomo. En este sentido podemos recordar la Resolución 59 de 14 diciembre de 1946 de la Asamblea General de la ONU, el art. 19 de la Declaración Universal de Derechos Humanos y el art. 19 del Pacto Internacional de Derechos Civiles y Políticos de 1966, textos internacionales que constituyen la base del derecho de acceso al reconocer que en estas libertades se integra el

\footnotetext{
9 De esta opinión L. COTINO HUESO, "Del "deber de publicidad" de Brandeis al "Open Government" de Obama. Regulación y control de la información pública a través de las nuevas tecnologías" en La protección de los Derechos Humanos por las Defensorías del Pueblo, G. ESCOBAR (dir.), Dykinson, Madrid, 2013.
} 
derecho a buscar y conocer información ${ }^{10}$. En el ámbito latinoamericano podemos reseñar como según la Relatoría Especial para la Libertad de Expresión (2013) "el derecho de acceso a la información ha sido considerado una herramienta fundamental para el control ciudadano en cuanto al funcionamiento del Estado y la gestión pública, en especial para el control de la corrupción; también para la participación ciudadana en asuntos públicos por medio del ejercicio informado de los derechos políticos y, en general, para la realización de otros derechos humanos, especialmente, de los grupos más vulnerables. El acceso a la información en poder del Estado es un derecho fundamental de los individuos. Los Estados están obligados a garantizar el ejercicio de este derecho".

En el ámbito europeo el Convenio Europeo de Derechos Humanos garantiza como libertad básica en las democracias la libre expresión e información en su art. 10, que ha sido profusamente desarrollado por la jurisprudencia del Tribunal Europeo de Derechos Humanos ${ }^{11}$. El art. 10 no menciona expresamente el derecho de acceso, que se integra en su ámbito, y en la intención de paliar el silencio del Convenio se dictó la Resolución 428, sobre medios de comunicación y derechos humanos, donde se declara que esta libertad incluye el derecho de buscar información y el correlativo deber de garantizar el acceso por parte de las autoridades siempre dentro de los límites establecidos ${ }^{12}$. El Comité de Ministros aprobó la Recomendación 19, sobre el acceso a la información en poder de las autoridades públicas y la Declaración sobre libertad de expresión e información. En su Recomendación sobre el acceso a los documentos oficiales ${ }^{13}$ sentará las bases de este derecho, ya que contiene

10 En el citado art. 19 de la Declaración Universal de Derechos Humanos se reconoce expresamente el derecho a "investigar y recibir informaciones" y en el párrafo $2^{\circ}$ del art. 19 del Pacto Internacional se reconoce "la libertad de buscar, recibir y difundir informaciones e ideas de toda índole".

${ }_{11}$ Sobre la construcción del régimen de ejercicio de las libertades de expresión e información ver mis trabajos: A. ABA CATOIRA, "La participación ciudadana en la administración de justicia a través del acceso a la información pública" en El paradigma del Gobierno Abierto. Retos y oportunidades de participación y colaboración, op. cit., pp. 6 y ss; "Protección de las libertades de expresión y sanción del odio en las democracias occidentales" en Anuario da Facultade de Dereito da Universidade da Coruña, 2015, 19, pp. 199-221.

${ }_{12}$ Resolución Núm. 428 sobre medios de comunicación masiva, de 23 de enero de 1970 .

13 Recomendación (2002) 2E, sobre acceso a documentos oficiales, de 21 de febrero de 2002. Las fuentes de esta Recomendación son: art. 19 de la Declaración Universal de Derechos Humanos; arts. 6,8 y 10 de la Convención Europea de Derechos Humanos y Libertades Fundamentales; Convención de las Naciones Unidas sobre el acceso a la información, la participación pública en la toma de decisiones y el acceso a la justicia en temas medioambientes (Declaración de Aarthus de 25 de junio de 1998); Convención para la protección de las personas con respecto al tratamiento automatizado de datos de carácter personal, de 28 de enero de 1981 (Convenio 108); Declaración sobre libertad de expresión e información de 29 de abril de 1982; Recomendación no. R (81) 19 sobre acceso a la información en poder de las autoridades; Recomendación no. R (91) 10 sobre la comunicación a terceras personas de datos de carácter personal en poder de organismos públicos; Recomendación nº. R (97) 18 sobre protección de datos personales recogidos y tratados con fines estadísticos; y la Recomendación nº. R (2000) 13 sobre política europea en el acceso a archivos. 
las normas mínimas de acceso que se integrarán en documentos posteriores, como ocurrió con el Convenio del Consejo de Europa aprobado en 2008, sobre el Acceso a los Documentos Públicos (Convenio 205) que por falta de ratificaciones no ha entrado en vigor.

El derecho de acceso se define en su art. 2.20 como "derecho a acceder, bajo petición, a los documentos públicos en posesión de las autoridades públicas y se corresponde con las obligaciones de tomar las medidas necesarias en su ordenamiento jurídico para hacer cumplir las previsiones sobre acceso a documentos públicos previstas en este Convenio". Se acompaña de una regulación amplia de los conceptos de autoridades públicas e información y se reducen las formalidades a fin de facilitar el ejercicio del derecho que, como es sabido, puede ser restringido según lo establecido legalmente.

Por lo que respecta a la labor jurisprudencial del Tribunal Europeo de Derechos Humanos resulta destacable que hasta fechas recientes no encontramos el reconocimiento del derecho de acceso. En la década de los 80 si se producen algunos pronunciamientos sobre el derecho de acceso a la información pública, aunque no se vincula al art. 10 sino a la vida privada garantizada en el art. 8 con base en que las solicitudes de información obedecen a motivos de esta naturaleza. En este orden de cosas, en STEDH Leander vs. Suecia, de 26 de marzo de 1987, además de vincular la solicitud de información al derecho a la vida privada, niega expresamente que el art. 10 del Convenio obligue a los poderes públicos a proporcionar o facilitar informaciones solicitadas ${ }^{14}$.

Ya en STEDH Sdruženi Jihočeske Matky v. Republica Checa, de 10 de julio de 2006, se aprecia un cambio en la argumentación del Tribunal Europeo puesto que señala que denegar la solicitud de acceso a la información afecta al derecho a recibir información garantizado en el art. 10 (si bien niega el derecho de acceso) que entendió que se limitaba de forma ajustada a Derecho. Por tanto, a partir de esta sentencia el Tribunal declara que el derecho de acceso a la información se integra en las libertades de expresión e información garantizadas en el art. 10 del Convenio Europeo de Derechos Humanos que cuenta con la regulación establecida en el Convenio 205.

En 2009 se dictaron dos sentencias contra Hungría en las que expresamente se va a reconocer el derecho de acceso a un historiador y a una ONG. En la primera de ellas, asunto Tarsasag a Szabadsagjogokert contra Hungria, de 14 de julio de 2009, reconoce abiertamente su voluntad de interpretar extensivamente la libertad de información y, por tanto, su posición más favorable al reconocimiento del derecho de acceso. En la misma línea se pronuncia en la segunda de ellas, asunto Kenedi $v$. Hungria, de 26 de agosto de 2009, en la que considera que la actitud obstruccionista y arbitraria por parte de las autoridades de impedir el acceso a la información, constituye un tipo de censura previa que vulnera

\footnotetext{
${ }^{14}$ En el mismo sentido, Sentencias Gaskin vs. Reino Unido, de 7 de julio de 1989; Guerra y otros vs. Italia, de 19 de febrero de 1998, sobre publicidad de la información en manos de la administración en materia de medio ambiente, entre otras.
} 
las libertades del art. 10. Este criterio del Tribunal se confirma posteriormente, en Youth Initiative for Human Rights c. Serbia, de 25 de septiembre de 2013.

En la Unión Europea se ha trabajado mucho en el ámbito de este derecho siendo clave su reconocimiento como derecho fundamental en la Carta de Derechos Fundamentales de la Unión Europea que se proclamó en el Consejo Europeo celebrado en Niza en diciembre de 2000. En esta declaración el derecho de acceso alcanzó su reconocimiento y garantía como derecho fundamental en el art. 41 de la Carta de Derechos Fundamentales de la Unión Europea como un derecho autónomo que, por tanto, no se integra en las libertades de expresión e información (a diferencia de su reconocimiento y desarrollo en el ámbito del Consejo de Europa) junto al derecho de acceso a los documentos públicos consagrado en el artículo 42.

Esta Carta adquirió valor jurídico con la entrada en vigor del Tratado de Lisboa en 2007 en aplicación de lo dispuesto en el art. 6.10 del Tratado de la Unión Europea. Con anterioridad, y con carácter preparatorio, podemos recordar algunas resoluciones del Parlamento Europeo que en la década de los 80 se manifestaba sobre la necesidad de reconocer un derecho a la información como derecho de la ciudadanía europea. No será hasta 1992 con Maastricht cuando podamos apreciar una clara voluntad comunitaria por articular un marco de transparencia donde el derecho de acceso se convierte en un elemento fundamental. A lo largo de estos años las instituciones comunitarias, con la excepción del Tribunal de Justicia de la Unión Europea, irán aprobando normas de acceso a la información.

Con el Tratado de Ámsterdam se introduce en el Derecho originario una regulación del derecho de acceso a los documentos obrantes en poder del Parlamento Europeo, el Consejo y la Comisión. Con la entrada en vigor del Tratado de Lisboa, este art. 255 se convierte en el art. 15 del Tratado de Funcionamiento de la Unión Europea. En toda esta secuencia de resoluciones y normas comunitarias hay que destacar la relevancia adquirida por el Libro Blanco de la Gobernanza europea ${ }^{15}$ donde se establece la conexión entre el principio de transparencia y el derecho de acceso a la información pública.

La regulación del derecho se produce con el Reglamento 1049/2001, de 30 de mayo de 2001, relativo al acceso del público a los documentos del Parlamento Europeo, del Consejo y de la Comisión que se ha revelado como un instrumento fundamental para la transparencia europea dado el incremento del número de documentos de las instituciones que son públicos y resultan accesibles para la ciudadanía.

Por lo que se refiere al Derecho español en la Constitución se reconoce un derecho a acceder a la información administrativa, pero en ningún caso un derecho fundamental de acceso a las informaciones públicas. Por tanto, no hay un derecho general de acceso pues se reconoce, con muchas limitaciones, dentro de un procedimiento administrativo en el art.105.b), y ello a pesar de que "en un sistema democrático donde el gobierno no deja

${ }^{15} \operatorname{COM}(2001) 428$ final. 
de ser el representante del pueblo, el derecho de acceso a la información se está convirtiendo paulatinamente en una herramienta esencial para que el ciudadano a través de su uso haga valer sus derechos frente al estado; de hecho es la naturaleza representativa del gobierno la que convierte al derecho de acceso a la información en un derecho fundamental"16.

Hasta la aprobación de la ley de transparencia estatal no se había producido una regulación general del derecho de acceso a la información sino algunas sectoriales ${ }^{17}$.

La regulación del derecho de acceso a la información del art. 105 b) CE contenida en esta Ley 30/1992, arts. 35, 37 junto al 3.50, se demostró insuficiente. De un análisis de dichos preceptos se concluye que el reconocimiento del derecho de acceso quedaba excesivamente limitado o recortado, pues se constreñía expresamente a documentos relacionados con procedimientos terminados y archivados, además de contener una lista de restricciones mucho más extensa que la prevista constitucionalmente además de ser limitaciones abiertas e indeterminadas.

Veremos más adelante la regulación del derecho de acceso introducida en la ley de transparencia estatal y concluiremos que, a pesar, de la innegable importancia de contar con una ley en esta materia, se ha desaprovechado una gran oportunidad para dotar de efectividad al derecho de acceso. No solo por su rango legal, a pesar de la posición de los tribunales internacionales y de otros Estados de nuestro entorno, que si lo han reconocido como un derecho fundamental por su conexión con las libertades del art. 20 de la Constitución ${ }^{18}$. En este sentido, en palabras de Olmedo Palacios: "El derecho de acceso es un derecho fundamental y no un derecho administrativo. El derecho de acceso a la información pública es un presupuesto capital de formación de la opinión pública, base fundamental del funcionamiento democrático de una comunidad política, al mismo nivel que la libertad de información y de la que forma parte según los textos internacionales en la materia y la jurisprudencia del TEDH. Su regulación como derecho meramente administrativo lo deja huérfano de la protección y garantías propias de los fundamentales, y prejuzga en su contra la ponderación de intereses que deberá realizarse

\footnotetext{
16 "El Derecho de acceso a la información: definición, protección internacional del derecho y principios básicos", Acces Info Europe, junio 2010, p. 3.

17 Sobre la elaboración de la ley de transparencia ver los comentarios de L. COTINO HUESO, "La nueva ley de transparencia y acceso a la información en España", en Anuario de la Facultad de Derecho de la Universidad de Alcalá, no 7, 2014, p. 5.

18 Sobre vinculación del derecho de acceso con las libertades del art. 20 ver entre otros M. SANCHEZ DE DIEGO, "Un derecho fundamental a acceder a la información pública", en M. SANCHEZ DE DIEGO (coord.), Derecho de acceso a la información pública, CERSA, Madrid, 2006; S. SOTO COSTAL, El derecho de acceso a la información, Tirant lo Blanch, Valencia, 2011, pp. 41 y ss; Ma. C. TORRES, "La fundamentalidad del derecho de acceso a la información pública: análisis crítico desde el marco constitucional de la participación ciudadana"; G. ROLNERT LIERN, "La ley de transparencia y el derecho de acceso: la discusión doctrinal y parlamentaria en torno a su naturaleza de derecho fundamental", en El paradigma del Gobierno Abierto. Retos y oportunidades, op. cit.
} 
administrativa y judicialmente para resolver los previsibles conflictos con otros derechos y bienes jurídicos"19.

Revisada la ley estatal es posible afirmar que la configuración del derecho resulta limitadora de su efectividad, pues el acceso no queda garantizado. Uno, por la naturaleza legal del derecho; y dos, por el elevado número de causas de inadmisión y el sistema de límites, excesivos, abiertos e indeterminados. Asimismo, resulta negativa la parquedad con la que regula el procedimiento sobre todo si atendemos a la importancia que reviste el derecho que se ejercita, el excesivo número de causas de inadmisión y de limitaciones o la ausencia de sanción en caso de incumplimiento de las obligaciones de publicidad. Ahora bien, resulta justo reconocer los logros o avances que se aprobación ha supuesto ya que esta establece deberes de publicidad activa donde antes no existían, regula el derecho de acceso con independencia de que se acredite un interés legítimo y nueva norma supone un progreso en la efectividad del principio de y no queda circunscrito a los archivos y registros públicos.

Por lo que se refiere al aspecto puramente formal, la ley estatal se estructura en tres títulos a lo largo de los cuales se distribuyen sus 40 artículos, más ocho disposiciones adicionales y nueve disposiciones finales, siendo el más interesante, a efectos de este trabajo, el Título I sobre "Transparencia de la actividad pública" donde se regula el ámbito subjetivo de aplicación; la publicidad activa y el derecho de acceso a la información pública.

En cuanto a los contenidos, de forma muy somera, indicaremos que la LETAI obliga a todas las administraciones públicas, si bien las comunidades autónomas han ido aprobando sus respectivas leyes que obligan a su administración propia y que suelen ser una reproducción de la ley de transparencia del Estado. Las aportaciones de las leyes autonómicas podrían resumirse, con carácter general, en un mayor número de obligaciones de publicidad activa, establecimiento de un régimen sancionador y la atribución de la garantía del derecho a instituciones independientes (caso de Galicia el Valedor do Pobo).

El acceso a las informaciones se hace efectivo a través de la publicidad activa y la publicidad pasiva, esto es, por la obligación de publicar de oficio y por la obligación de satisfacer el derecho de la ciudadanía ejercitado a través de la solicitud de información. Se establece la regulación del procedimiento de publicación así como los contenidos que han de ser publicados, desplegando su eficacia limitadora la enumeración contenida en el art. $14^{20}$ y sobre todo el derecho de protección de datos

\footnotetext{
${ }^{19}$ M. OLMEDO PALACIOS, "La Ley 19/2013, de 9 de diciembre, de Transparencia, Acceso a la información pública y Buen Gobierno" en Diario La Ley, n' 8237 , de 27 de enero de 2014.

${ }^{20}$ El listado es el siguiente: la seguridad nacional, la defensa, las relaciones exteriores, la seguridad pública, la prevención, investigación y sanción de los ilícitos penales, administrativos o disciplinarios, la igualdad de las partes en los procesos judiciales y la tutela judicial efectiva, las funciones administrativas de vigilancia, inspección y control, los intereses económicos y comerciales, la política económica y monetaria, el secreto
} 
personales regulado en el art. 15 , por lo que muchas informaciones no serán accesibles.

La ley de transparencia crea una institución de control que es el Consejo de Transparencia y Buen Gobierno (art. 35), un organismo adscrito al Ministerio de Hacienda y Administraciones Públicas que actúa con independencia y autonomía. A lo largo del tiempo que lleva funcionando es destacable la aprobación de un Informe de 2012 y del Plan Nacional de Transparencia.

Bien es cierto que tanto la lista de sujetos obligados (arts. 2 y 4 ) como el concepto de información pública son muy amplios, así, ésta queda definida en el art. 13 como todo contenido "cualquiera que sea su formato o soporte, que obren en poder de alguno de los sujetos incluidos en el ámbito de aplicación de este título y que hayan sido elaborados o adquiridos en el ejercicio de sus funciones". Ahora bien, la efectividad del derecho se ve constreñida por las causas que justifican la inadmisión de las solicitudes contenidas en el art. 18.

Sobre el derecho de acceso varias son las cuestiones que no por conocidas han de ser obviadas en este trabajo: la naturaleza del derecho que en nuestro ordenamiento no ha adquirido el rango de fundamental; el número a todas luces excesivo de limitaciones del que es objeto; la falta de voluntad de favorecer el acceso, etc.

\section{EL DERECHO DE ACCESO EN LA LEY GALLEGA}

Resulta necesario hacer un pequeño ejercicio de memoria trayendo a estas páginas la derogada Ley Gallega 4/2006, de Transparencia y Buenas Prácticas, que ha sido la antecesora de la que ahora nos ocupa, pues su contenido responde a los principios de transparencia, buenas prácticas y participación ciudadana. Así, declara que, en un modelo de gobierno regido por los principios de transparencia, información y responsabilidad, la participación en los asuntos públicos es un derecho fundamental.

Los principios que regirán la actividad de la administración en la nueva LGT son (art. 2):

a) Procurar la satisfacción del interés general en la toma de decisiones. b) Garantizar la transparencia, la eficacia y la eficiencia en la organización y en la gestión pública. c) Proporcionar y difundir información constante, veraz, objetiva y clara sobre la actuación del sector público autonómico. d) Potenciar su accesibilidad y receptividad al objeto de facilitar el conocimiento por parte de la ciudadanía de las informaciones y gestiones que resulten de su interés. e) Fomentar y favorecer la participación de la ciudadanía en los asuntos públicos y en el diseño y mejora de los servicios públicos $y$, en particular, la participación equilibrada de las mujeres y los hombres en los asuntos públicos. f) Mantener un diálogo abierto, transparente y regular con las asociaciones representativas y con la sociedad civil. g) Garantizar en sus relaciones con la ciudadanía el principio de no discriminación por razón de género, raza, religión o 
creencia, ideología, capacidad física o psicológica, o cualesquiera otras circunstancias de índole personal o social. Se buscará especialmente y en los términos contemplados en la Ley 7/2004 la eliminación absoluta de las discriminaciones directas e indirectas. h) Hacer efectivos los principios de racionalidad, claridad y confianza legítima en la relación de la Administración con los ciudadanos. i) Impulsar el empleo de las técnicas informáticas y telemáticas para el desarrollo de su actividad y el ejercicio de sus competencias. j) Promover el uso normal del gallego, oralmente o por escrito, en las relaciones con la ciudadanía, sin perjuicio del derecho de no discriminación por razones de la lengua. k) Prestar especial atención a las necesidades de las personas discapacitadas, adoptando las medidas necesarias para facilitar su acceso a la información y sus relaciones con la Administración.

La ley objeto de análisis se estructura en un Título Preliminar y tres títulos dedicados cada uno de ellos a los objetivos establecidos en el nombre de la misma. En el Título Preliminar se abordan el objeto de la ley establece los principios que rigen su aplicación que emanan de los principios democráticos "generales" de transparencia y publicidad que rigen la actividad pública. Estos principios rectores se enumeran en el art. 2:

- Principio de transparencia que supone que toda la información pública es accesible y relevante y que toda persona tiene reconocido el acceso libre y gratuito a dicha información excepto en los casos previstos en la ley

- Principio de accesibilidad universal de la información pública

- Principio de participación ciudadana que se traduce en que el acceso garantiza la obtención de información para ejercitar el derecho fundamental de participación en los asuntos públicos (art. $23 \mathrm{CE}$ )

- Principio de veracidad de la información

- Principio de responsabilidad de los sujetos obligados por la ley

- Principio de no discriminación tecnológica ni lingüística

- Principio de reutilización de la información

- Principio de integridad, honestidad, imparcialidad, objetividad y respeto del marco jurídico y de la ciudadanía

Por lo que se refiere al Título I (Transparencia) éste se estructura en cinco capítulos dedicados consecutivamente a establecer los sujetos obligados por la ley, así como a identificar a otros sujetos que han de prestar su colaboración para garantizar el acceso ciudadano a la información siendo destacable como novedad introducida la previsión de multas en caso de que esta colaboración no sea prestada. En el Capítulo II se establecen las obligaciones de publicidad activa, siendo más que las que se fijan en la legislación básica, suponiendo un notable incremento respecto a las contenidas en la Ley 4/2006, de 30 de junio, de Transparencia y Buenas Prácticas en la Administración Pública Gallega, que ya resultaba insuficiente. Se incrementa con la nueva regulación no solo la cantidad de contenidos que han de ser públicos sino la calidad o el mismo formato en que se ofrecen. En relación con este aspecto en el Capítulo III se dota de 
preferencia a los datos abiertos que permiten la reutilización de a información suministrada.

El Capítulo IV de este Título es el dedicado a la regulación del derecho de acceso que será analizado en las páginas siguientes.

En el último de los capítulos del Título I se establecen los mecanismos de coordinación y control del cumplimiento de las obligaciones de transparencia, regulándose el Portal de Transparencia y Gobierno abierto. El aspecto quizás más novedoso es la determinación del órgano independiente que tendrá la competencia para resolver las reclamaciones presentadas contra las resoluciones denegatorias de las solicitudes de acceso a la información. Esta garantía, posibilidad que establece la Disposición Adicional cuarta de la LETAI, se ejercitará por el Valedor del Pueblo ${ }^{21}$.

Por lo que atañe al Título II en él se recogen los mecanismos de Buen gobierno y control de la actividad de los altos cargos en el sector público autonómico. El último de los Título, Título III, establece el régimen sancionador. Esta ley también contiene disposiciones, seis adicionales, tres transitorias, una derogatoria y cinco finales.

\subsection{Concepto del derecho de acceso}

Ya se ha afirmado que el derecho de acceso es un derecho de transparencia $y$, en este sentido, es un derecho nuevo, emergente, un derecho de última generación muy conectado a las nuevas tecnologías.

Revisada la normativa y jurisprudencial internacional y europea, así como las normas y doctrina española es posible proponer una definición del derecho. En este sentido, el derecho de acceso a la información pública es la facultad que corresponde a la ciudadanía de conocer toda información pública que obre en poder del Estado $o$ en de sujetos privados que desarrollan funciones públicas u obtienen fondos o subvenciones públicas y este derecho obliga a los poderes públicos a gestionar esta información y garantizar el acceso solicitado.

El acceso como derecho subjetivo puede exigirse frente a terceras personas públicas o privadas y, en último caso, ante los órganos judiciales garantes de los derechos y libertades.

\subsection{Aspectos sustantivos: concepto de información pública, titularidad y limitaciones}

El derecho de acceso a la información pública ha sido regulado por el legislador estatal y por los parlamentos autonómicos a partir de su reconocimiento en el art. 105 b) de la $C E$, y, por tanto no como un derecho fundamental tal como se ha visto. En la ley estatal se regula en sus arts. 12 a 24 ubicados en el Título I- Capítulo III. El legislador lo reconoce en su art. 12 como derecho que corresponde a "todas las

\footnotetext{
${ }^{21}$ Sobre esta institución consultar su Ley propia Ley 6/1984, de 5 de junio, del Valedor do Pobo (modificada por las Leyes 3/1994, de 18 de julio; 1/2002, de 26 de marzo, 8/2008, de 10 de julio; 10/2012, de 3 de agosto y 1/2016, de 18 de enero).
} 
personas" en los términos establecidos en el art. 105 b). Asimismo, se refiere a las regulaciones establecidas por las Comunidades Autónomas en sus ámbitos competenciales siendo reseñable que ha sido en este nivel donde se ha llevado a cabo una buena adecuación de los principios y derechos de transparencia sobre todo a través de los derechos de democracia participativa ${ }^{22}$.

${ }^{22}$ En el ámbito autonómico las políticas de transparencia están así:

Andalucia: Ley 1/2014, de 24 de junio, de Transparencia Pública de Andalucía http://www.juntadeandalucia.es/transparencia.html

Consejo de Transparencia y Protección de Datos de Andalucía

Aragón: http://transparencia.aragon.es/

Ley 8/2015, de 25 de marzo, de Transparencia de la Actividad Pública y Participación Ciudadana de Aragón.

Canarias: http://www.gobiernodecanarias.org/transparencia/

Ley $12 / 2014$, de 26 de diciembre, de transparencia y de acceso a la información pública.

Cantabria: http://transparencia.cantabria.es/

Castilla La Mancha: http://transparencia.castillalamancha.es/

Castilla y León: http://www.gobiernoabierto.jcyl.es/

Ley $3 / 2015$, de 4 de marzo, de Transparencia y Participación Ciudadana de Castilla y León.

https://www.procuradordelcomun.org/

Cataluña: http://transparencia.gencat.cat/es/inici/

Ley 19/2014, de 29 de diciembre, de transparencia, acceso a la información pública y buen gobierno.

http://www.gaip.cat/ca/inici/

Ceuta: http://consejodetransparencia.es

Extremadura: http://gobiernoabierto.gobex.es/

Ley 4/2013, de 21 de mayo, de Gobierno Abierto de Extremadura.

Galicia: http://transparencia.xunta.gal/portada

Ley $1 / 2016$, de 18 de enero, de transparencia y buen gobierno

http://www.valedordopobo.gal/es/

Islas Baleares:

http://www.caib.es/sacmicrofront/home.do?mkey=M1102141103432671913

Ley $4 / 2011$, de 31 de marzo, de la buena administración y del buen gobierno de las Illes Balears

La Rioja: http://www.larioja.org/portal-transparencia/es

Ley 3/2014, de 11 de septiembre, de Transparencia y Buen Gobierno de La Rioja

Comunidad de Madrid:

http://www. madrid.org/cs/Satellite?c=Page\&cid $=1350930987804 \&$ pagename $=$ Comunida dMadrid/Page/CM_servicioPrincipal

\section{Melilla:}

http://www.melilla.es/melillaportal/contenedor.jsp?seccion=s_fdes_d4_v1.jsp\&contenido $=16471 \&$ nivel $=1400 \&$ tipo $=6 \&$ codResi $=1 \&$ language $=$ es $\&$ codMenu $=535 \& \operatorname{cod}$ MenuPN $=601$

\&codMenuSN $=1 \&$ codMenuTN $=135$

Navarra: http://www.gobiernoabierto.navarra.es/es/transparencia

Ley Foral 11/2012, de 21 de junio, de la Transparencia y del Gobierno Abierto

País Vasco: http://www.gardena.euskadi.eus/y09-inicio/es/

http://www.irekia.euskadi.eus/es/debates/1049-proyecto-ley-transparencia-

participacion-ciudadana-buen-gobierno-del-sector-publico-vasco?stage =conclusions

\section{Principado de Asturias:}

https://www.asturias.es/portal/site/webasturias/menuitem.90f2ec149cf8a1dc8b8a89c6e c12b2a0/?vgnextoid=babf7f42a8d69310VgnVCM10000098030a0aRCRD\&vgnextchannel= dad56fc85c97d210VgnVCM1000002f030003RCRD\&i18n.http.lang=es 
Por tanto, lo más destacable es la universalización del derecho de acceso "todas las personas" siendo titulares las personas físicas y las jurídicas, las públicas y las privadas, las nacionales y las extranjeras, superando el criterio de la ciudadanía establecido en el art. 105 b) de la CE y 37 de la Ley 30/1992. Esta configuración resulta mucho más acorde con los principios de publicidad y transparencia que han de regir las relaciones entre la ciudadanía y las administraciones. En todo caso, no está de más recordarlo, el ejercicio de este derecho será siempre en igualdad de condiciones respetando las previsiones del art. $14 \mathrm{CE}$.

En línea con la ley estatal la Ley gallega en su art. 24 declara que "todas las personas tienen derecho a acceder a la información pública en los términos previstos en la normativa básica en materia de transparencia".

El acceso se refiere a la información pública que será según el art. 13 de la LETAI todo contenido "cualquiera que sea su formato o soporte, que obren en poder de alguno de los sujetos incluidos en el ámbito de aplicación de este título y que hayan sido elaborados o adquiridos en el ejercicio de sus funciones". Según el art. 24 de la LGT son "los contenidos o documentos, cualquiera que sea su formato o soporte, que obren en poder de alguno de los sujetos incluidos en su ámbito de aplicación y que hayan sido elaborados o adquiridos en el ejercicio de sus funciones". Asimismo, se considera información pública "la producida por las entidades que presten servicios públicos 0 ejerzan potestades administrativas en los términos establecidos en el art. 4 de la ley".

Al analizar el concepto de información pública hemos de tener en cuenta la doble vertiente del principio de publicidad, activa y pasiva, pues un volumen considerable de información se publica activamente, garantizando el derecho de acceso a un volumen importante de contenidos sin tener que realizar ninguna solicitud o requerimiento dando respuesta a la obligación legal de informar. Así se ofrece información actualizada y completa al público ya sea directamente en sus webs o enlazando con links ${ }^{23}$. Es conveniente poner de manifiesto la falta de desarrollo de los formatos electrónicos en los que se pone a disposición del público la información, pues si se pretende garantizar la reutilización de la información pública se debe potenciar el uso de las nuevas tecnologías y las plataformas sociales desde las instituciones.

Por lo que se refiere a la información qué debe ser publicada la ley estatal establece unos contenidos mínimos que las Comunidades Autónomas y entes locales pueden aumentar según establece el art. 5.10.

Región de Murcia: http://transparencia.carm.es/

Ley 12/2014, de 16 de diciembre, de Transparencia y Participación Ciudadana de la Comunidad Autónoma de la Región de Murcia.

Comunidad Valenciana: http://www.gvaoberta.gva.es/inici

Ley $2 / 2015$, de 2 de abril, de Transparencia, Buen Gobierno y Participación Ciudadana de la Comunitat Valenciana.

23 Todas las instituciones cuentan con Portal de Transparencia, pueden consultarse en http://transparencia.gob.es/transparencia/transparencia_Home/index/Mas-

Transparencia/Instituciones-publicas.html 
En el párrafo $2^{0}$ del art. 24 se detallan una serie de elementos indispensables para garantizar el derecho de acceso a la información pública:

- La posibilidad de utilizar la información obtenida sin necesidad de obtener autorización previa y sin más limitaciones que las derivadas de esta u otras leyes

- La recepción de la información pública en formato electrónico o en papel según haya indicado la persona solicitante

- La recepción de la información pública en la lengua oficial de Galicia en la que la solicite

- El conocimiento de las tasas y precios que, en su caso, sean exigibles para la obtención de copias o para la transposición de la información a formatos diferentes del original

- La realización de propuestas y sugerencias tanto sobre la información demandada como sobre los formatos, programas o lenguajes informáticos empleados

Según se establece en el último párrafo de este artículo el ejercicio de este derecho por los parlamentarios autonómicos se regula en su normativa específica. Así, podemos recordar que el art. 9 del Reglamento del Parlamento de Galicia les reconoce para el mejor ejercicio de sus funciones la "facultad de solicitar de las administraciones públicas los datos, informes o documentos que consten en poder de estas". La Administración debe facilitar la documentación solicitada o manifestar a la Presidencia en plazo no superior a treinta días las razones fundadas en derechos que impidan esa comunicación o comunicar su disposición para permitir el acceso directo a la información solicitada. En caso de incumplimiento por la Administración las solicitudes se pueden reconvertir en pregunta en comisión donde serán tratadas como preguntas orales.

Los parlamentarios también tienen derecho a recibir directamente 0 a través de su grupo la información o documentación que necesiten para desarrollar sus funciones estando obligados los Servicios Generales de la Cámara a facilitarla.

En el artículo 44 se prevé otro mecanismo de acceso a la información en cuanto que órgano colegiado de funcionamiento pues las comisiones, a través del Presidente del Parlamento, pueden pedir la información y documentación que necesiten de las instituciones autonómicas y entes públicos o a las autoridades del Estado. Asimismo, pueden requerir la presencia de los miembros de la Xunta de Galicia competentes por razón de la materia que se debata, para que informen sobre todas las cuestiones sobre las que sean consultados y pueden solicitar la presencia de funcionarios, autoridades y particulares cuyo incumplimiento puede conllevar exigencias de responsabilidad.

Las normas reguladoras de la transparencia y publicidad de las actuaciones de los poderes públicos no siempre han resultado de aplicación a todos los poderes pues tradicionalmente se dirigieron a controlar la actuación del poder ejecutivo. En este sentido, no ha habido uniformidad a la hora de establecer en las leyes quienes son los sujetos obligados siendo bastante común que la publicidad de las actuaciones de 
los poderes distintos al ejecutivo y de otros sujetos públicos quedase regulada a través de normas sectoriales. En este orden de cosas, el Convenio 205 ya citado se mostraba mucho más favorable a la ampliación del ámbito de los sujetos obligados que lo que las legislaciones nacionales han demostrado en la práctica.

Por lo que se refiere a la LETAI lo cierto es que el listado es extenso, pues los arts. 2-4 y 5 contienen una extensa enumeración incluyendo a las Administraciones Públicas, organismos autónomos, agencias estatales, entidades públicas empresariales y entidades de derecho público que tengan funciones de regulación o control sobre un determinado sector o actividad, así como a las entidades de Derecho Público con personalidad jurídica propia, vinculadas o dependientes de cualquiera de las administraciones públicas, incluidas las universidades públicas. De otra parte, se incluyen las entidades gestoras y los servicios comunes de la Seguridad Social, las mutuas de accidentes de trabajo y enfermedades profesionales colaboradoras de la Seguridad Social. Asimismo, la Ley obliga en sus actividades sujetas a Derecho Administrativo a las corporaciones de Derecho Público, al Congreso de los Diputados, al Senado, al Tribunal Constitucional y al Consejo General del Poder Judicial, al Consejo de Estado, al Defensor del Pueblo, al Tribunal de Cuentas, al Consejo Económico y Social, así como a estas instituciones cuando existan en el ámbito autonómico. No cabe olvidar a la Casa de Su Majestad el Rey y al Banco de España. En el listado aparecen las sociedades mercantiles cuando en su capital social se da una participación directa o indirecta superior al cincuenta por ciento, las fundaciones del sector público y las asociaciones constituidas por las Administraciones, organismos y entidades ya citados. Asimismo, quedan obligados los partidos políticos, los sindicatos y las organizaciones empresariales sin olvidar entidades de carácter privado que hayan recibido ayudas económicas establecidas en la ley.

Por lo que se refiere a la LGT estos sujetos son los que obran a continuación según la relación contenida en su art. 3:

- Sector público autonómico

- Universidades del Sistema Universitario de Galicia y entidades vinculadas o dependientes

- Las corporaciones de Derecho Público que desarrollan su actividad exclusivamente en la Comunidad Autónoma, en lo que se refiere a sus actividades sujetas a Derecho Administrativo

- Parlamento de Galicia, Consejo Consultivo, Valedor del Pueblo, Consejo de Cuentas, Consejo Económico y Social, Consejo Gallego de Relaciones Laborales y Consejo de la Cultura Gallega, en sus actividades sujetas a Derecho Administrativo y en todo caso respecto a los actos en materia de personal y contratación

- A todos los entes, organismos o entidades con personalidad jurídica propia que se creasen específicamente para satisfacer necesidades de interés general sin carácter industrial o mercantil siempre que los sujetos anteriormente citados financien mayoritariamente su 
actividad, controlen su gestión o nombren a más de la mitad de los miembros de su órgano de administración, dirección o vigilancia.

- Asociaciones que hayan constituido los sujetos citados

A pesar del concepto amplio de información pública que manejan los legisladores, lo cierto es que el ejercicio del derecho de acceso se ve negativamente afectado por el excesivo número de causas de inadmisión que suponen la imposibilidad de la plena realización del derecho. Efectivamente, el art. 18 de la LETAI deja fuera del ejercicio del derecho a la información en curso de elaboración o de publicación general; a la información auxiliar o de apoyo como notas, borradores, opiniones, resúmenes, comunicaciones $\mathrm{e}$ informes internos 0 entre órganos 0 entidades administrativas. Se excluye también el acceso a la información para cuya divulgación sea necesaria una acción previa de reelaboración.

Si las causas de inadmisión previstas legalmente parecen excesivas la efectividad del derecho se ve potencialmente amenazada por los excesivos límites que le afectan por razón de la protección de otros derechos o intereses constitucionalmente protegidos ${ }^{24}$. Es en el art. 14 de la LETAI donde se enumeran estas causas: la seguridad nacional, la defensa, las relaciones exteriores, la seguridad pública, la prevención, investigación y sanción de los ilícitos penales, administrativos o disciplinarios, la igualdad de las partes en los procesos judiciales y la tutela judicial efectiva, las funciones administrativas de vigilancia, inspección y control, los intereses económicos y comerciales, la política económica y monetaria, el secreto profesional y la propiedad intelectual e industrial, la garantía de la confidencialidad o el secreto requerido en procesos de toma de decisión, la protección del medio ambiente ${ }^{25}$.

${ }^{24}$ Una elaboración de una teoría general sobre los límites de los derechos en $A$. ABA CATOIRA, La limitación de los derechos en la jurisprudencia del Tribunal Constitucional, Tirant lo Blanch, Valencia, 1999.

${ }^{25}$ En esta nota introducimos información extraía de la web que nos permite estudiar las solicitudes de acceso que han sido denegadas, en este sentido, los límites aparecen ordenados y podemos conocer la causa de denegación, Ministerio responsable y consulta planteada.

http://transparencia.gob.es/transparencia/transparencia_Home/index/Derecho-deacceso/Todo-sobre-derecho-de-acceso/Resoluciones-denegatorias.html

1. La seguridad nacional (art. 14.1.a).

2. La defensa (art. 14.1.b).

3. Las relaciones exteriores (art. 14.1.c).

4. La seguridad pública (art. 14.1.d).

5. La prevención, investigación y sanción de los ilícitos penales, administrativos o disciplinarios (art. 14.1.e).

6. La igualdad de las partes en los procesos judiciales y la tutela judicial efectiva (art. 14.1.f).

7. Las funciones administrativas de vigilancia, inspección y control (art. 14.1.g).

8. Los intereses económicos y comerciales (art. 14.1.h).

9. La política económica y monetaria (art. 14.1.i).

10. El secreto profesional y la propiedad intelectual e industrial (art. 14.1.j).

11. La garantía de la confidencialidad o el secreto requerido en procesos de toma de decisión (art. 14.1.k).

12. La protección del medio ambiente (art. 14.1.I). 
Un listado que, como se comprueba con una rápida lectura, resulta a todas luces excesivo, cuando la ley pretende regular y garantizar el ejercicio de un derecho constitucional íntimamente relacionado con la transparencia y con derechos básicos en democracia como las libertades de información y el derecho a participar en los asuntos públicos. Cierto es que en la ley se establecen expresamente los parámetros o criterios a tener en cuenta en la ponderación necesaria para determinar si prevalece el derecho de acceso o aquel otro derecho o interés con el que colisiona, pues, como bien es sabido, la efectividad de todos ellos requiere un balance, una armonización que obliga a encontrar en la medida de posible un punto de equilibrio de modo que la prevalencia de uno no haga desaparece al otro. Así, en el Preámbulo se dice que "los límites previstos se aplicarán atendiendo a un test de daño y de interés público en la divulgación y de forma proporcionada y limitada por su objeto y finalidad" completándose con las previsiones del art. $14.2^{\circ}$ que establece que "la aplicación de los límites será justificada y proporcionada a su objeto y finalidad de protección y atenderá a las circunstancias del caso concreto, especialmente a la concurrencia de un interés público o privado superior que justifique el acceso". Así las cosas, la garantía del derecho (muy afectado por casos en los que nunca se concederá el acceso) se hace depender de una decisión ponderada donde siempre juega en casa el derecho de protección de datos y la privacidad, ante la fuerte protección que les otorga el ordenamiento y de la que es conocedor quien resuelve la solicitud de acceso a la información.

La LGT en su art. 25 relativo a las limitaciones del derecho se limita a decir que "solo podrá ser limitado o denegado en los supuestos previstos en la normativa básica". El párrafo $2^{\circ}$ recoge el principio de proporcionalidad de las limitaciones que siempre se interpretarán restrictivamente y añade una coletilla que, a mi juicio, trasluce la voluntad predeterminada de dar prevalencia a otros derechos o intereses con los que el derecho de acceso entra en conflicto salvo en supuestos muy excepcionales. Esta consideración la realizamos ya que establece que "se aplicarán (las limitaciones) a menos que un interés público o privado superior justifique la divulgación de la información". Siendo ya conocida la protección que se dispensa a la protección de datos personales y a la vida privada así como el rango no fundamental del derecho de acceso a partir de la regulación del art. 15 de la LETAI podemos concluir varias cosas. En primer lugar, no es posible acceder a informaciones de terceras personas que versen sobre su ideología, afiliación sindical, religión y creencias $^{26}$; en todo caso, el acceso requiere el consentimiento expreso de la persona titular de los datos solicitados o autorización legal para acceder a datos catalogados como especialmente protegidos o relativos a causas 0 infracciones penales o administrativas. Entendemos que estas previsiones

Ver las resoluciones que incluyen varias causas de denegación (art. 14.1).

${ }^{26}$ Estos son los datos especialmente protegidos según reza el art. 7.20 Ley Orgánica 15/1999, de Protección de Datos Personales. 
del $15.1 .1^{\circ}$ y $2^{\circ}$ cierran la puerta al acceso al no establecerse que haya que estar al caso $y$, en consecuencia, determinar qué derecho prevalecerá, pues si así fuera en algunos supuestos se podría concluir la prevalencia del derecho a saber o conocer y autorizar el acceso.

A continuación en el $15.1 .3^{\circ}$ se establece que en los demás casos, cuando no hay datos especialmente protegidos en juego, se realizará una ponderación entre el interés público que estriba en la divulgación y el derecho de protección de datos u otros derechos afectados si la información que se solicita afecta a datos meramente identificativos o relacionados con la organización, funcionamiento o actividad pública del órgano.

La ley se ocupa de establecer unos criterios para solucionar los conflictos surgidos en la práctica y que han de resolverse con la pertinente ponderación. Así, para resolver la solicitud de acceso favorablemente son elementos de peso, el transcurso del tiempo de los plazos que se establecen en la ley de patrimonio histórico español, que se trate de una solicitud en el marco de una investigación, que sean datos meramente identificativos (como señala expresamente) o que no se produzca una afectación intensa en la intimidad o seguridad o que no se trate de menores de edad o que hayan sido disociados.

Lo anterior supone que en la aplicación del alcance y efectos de la excepción habrá que realizar la oportuna ponderación o balance entre los intereses en juego, lo que supone que no existan soluciones estandarizadas al responder al caso concreto o casuística. Esta operación le corresponde en primer lugar al funcionario que tiene que informar sobre la solicitud recibida y posteriormente a la autoridad que debe resolver sobre la solicitud.

\subsection{Cuestiones procedimentales}

Llegados a este punto resulta necesario hacer algunas consideraciones sobre el procedimiento de acceso regulado en el art. 26 y ss. de la LGT. La persona solicitante dirigirá su solicitud al sujeto que posea la información, la Administración establece un sistema integrado de atención a la ciudadanía desde donde se gestionan las solicitudes de información (art. $26.2^{\circ}$ ). La ley pretende fomentar las solicitudes electrónicas por lo que la Administración a través del Portal de Transparencia y Gobierno abierto de Galicia proporcionará modelos normalizados de solicitud y la posibilidad de enviarla a la Administración requerida (art. 26.30). Resulta particularmente positivo el objetivo de potenciar los formatos electrónicos para presentar y tramitar las solicitudes de acceso, un aspecto que se echa en falta en la ley estatal, tal como se indicó.

La ley no obliga a motivar la solicitud de acceso pero tal como indica el párrafo $4^{\circ}$ del art. 26 estos motivos podrán ser tenidos en cuenta cuando se dicte la resolución, por lo que su exposición puede resultar positiva para resolver a su favor la solicitud. Si la información solicitada afectase a terceras personas se le concederá un plazo de quince días para formular alegaciones (art. 27.10). 
Todas las resoluciones serán notificadas a quien solicitó el acceso y a los terceros que lo hubiesen solicitado como muy tarde en el plazo de un mes desde que se recibió la solicitud por el órgano competente para resolver ${ }^{27}$. Obviamente, las resoluciones denegatorias o aquellas que conceden un acceso parcial estarán motivadas (art. $20.2^{\circ}$ LETAI) si bien cabe poner fin al procedimiento por silencio negativo ya que transcurrido el plazo para resolver sin que se hubiera dictado una resolución, se entenderá que ha sido desestimada (art. 20.40 LETAI y art. 27 LGT).

Contra toda resolución ya sea expresa o presunta se puede interponer una reclamación. La LETAI establece en su art. 24 que esta competencia le corresponde al Consejo de Transparencia y Buen Gobierno salvo que en la Comunidad Autónoma de referencia se hubiera atribuido a un órgano específico. En su Disposición adicional cuarta establece que la resolución de la reclamación corresponderá, en los supuestos de resoluciones dictadas por las Administraciones de las Comunidades Autónomas y su sector público, y por las Entidades Locales comprendidas en su ámbito territorial, al órgano independiente que determinen las comunidades autónomas. Asimismo establece que las comunidades autónomas podrán atribuir dicha competencia para la resolución de las reclamaciones al Consejo de Transparencia y Buen Gobierno, celebrando al efecto un convenio. A estos efectos la LGT atribuye el conocimiento de las reclamaciones al Valedor do Pobo (excepto si quien la dicta es uno de los sujetos previstos en el $3.1^{\circ} \mathrm{d}$ ) ya que contra estas resoluciones solo cabe recurso contencioso-administrativo) que vendrá a sustituir los recursos administrativos, con carácter potestativo y previo a la impugnación contencioso-administrativa ${ }^{28}$. Tal como queda dicho, una vez finalizada la fase administrativa o presentada reclamación ante el Valedor, la denegación de la solicitud de acceso puede someterse ante las autoridades judiciales que para resolver el litigio realizarán la pertinente operación ponderadora.

Ya para cerrar este trabajo poner de manifiesto la importancia que tiene junto al régimen de recursos administrativos y de naturaleza judicial, la regulación de un régimen sancionador frente a la administración incumplidora, ya sea por no dar efectividad al principio de publicidad activa ya sea por hacer del silencio o la denegación la norma en sus resoluciones de las solicitudes de acceso. En este sentido, la LGT da un paso más al regular un completo régimen sancionador en su Título III.

\footnotetext{
27 Según establece el art. $27.3^{\circ}$ en el ámbito del sector público autonómico, la competencia para la resolución de las solicitudes de acceso le corresponde a la persona titular de la Secretaría General, la Secretaría General Técnica, la Dirección General o la Delegación territorial en el caso de la Administración general de la Comunidad Autónoma, y a la persona titular de los órganos de gobierno o ejecutivos de las entidades instrumentales del sector público que posean la información.

28 Las resoluciones dictadas por el Valedor do Pobo se publicarán en el Portal de Transparencia y Gobierno abierto una vez se hayan notificado y previa disociación de los datos de carácter personal (art. 28.4º).
} 


\section{BIBLIOGRAFIA}

XIII Informe sobre Derechos Humanos "Transparencia e Información Pública", G. ESCOBAR (dir.), Federación Iberoamericana de Ombudsman, Trama Editorial, Madrid, 2015.

ABA CATOIRA, A., La limitación de los derechos fundamentales en la jurisprudencia del Tribunal Constitucional, Tirant lo Blanch, Valencia, 1999.

ABA CATOIRA, A., "La participación ciudadana en la administración de justicia a través del acceso a la información pública" en L. Cotino Hueso, J. L. Sahuquillo y L. Corredoira (eds.), El paradigma del Gobierno Abierto. Retos y Oportunidades de participación y colaboración, Universidad Complutense de Madrid, 2015, pp.180195.

ABA CATOIRA, A., "Protección de las libertades de expresión y sanción del odio en las democracias occidentales" en Anuario da Facultade de Dereito da Universidade da Coruña, 2015, 19: 199-221

ACKERMAN, R., Corruption and Government: Causes, Consequences and Reform, Cambridge, Cambridge University Press.

COTINO HUESO, L., "Del "deber de publicidad" de Brandeis al "Open Government" de Obama. Regulación y control de la información pública a través de las nuevas tecnologías" en G. Escobar Roca (dir.), La protección de los Derechos Humanos por las Defensorías del Pueblo", Dykinson, Madrid, 2013.

COTINO HUESO, L., "La nueva ley de transparencia y acceso a la información en España", en Anuario de la Facultad de Derecho de la Universidad de Alcalá, 2014,7.

COTINO, L, SAHUQUILLO, J. L. Y CORREDOIRA, L, (eds), El paradigma del Gobierno Abierto. Retos y Oportunidades de participación y colaboración, Universidad Complutense de Madrid, 2015.

FERNANDEZ RODRIGUEZ, J. J., "La aprehensión jurídica de la democracia y el gobierno electrónicos", en L. Cotino Hueso (coord.), Libertades, democracia y gobierno electrónico, Comares, Granada, 2006.

FERNÁNDEZ SALMERÓN, M, VALERO TORRIJOS, J. (coords), Régimen jurídico de la transparencia en el sector público: acceso, uso y reutilización de la información administrativa, Thomson-Aranzadi, Madrid, 2014.

GUICHOT REINA, E. (coord.), Transparencia, Acceso a la Información Pública y Buen Gobierno, Tecnos, Madrid, 2014.

OLMEDO PALACIOS, M., "La Ley 19/2013, de 9 de diciembre, de Transparencia, Acceso a la información pública y Buen Gobierno" en Diario La Ley, no 8237, de 27 de enero de 2014.

ROLNERT LIERN, G., "La Ley de Transparencia y el derecho de acceso: la discusión doctrinal y parlamentaria en torno a su naturaleza de Derecho Fundamental" en L. Cotino Hueso, J. L. Sahuquillo y L. Corredoira (eds.), El paradigma del Gobierno Abierto. Retos y Oportunidades de participación y colaboración, Universidad Complutense de Madrid, 2015, pp. 105-114. 
SANCHEZ DE DIEGO, M., "Un derecho fundamental a acceder a la información pública" en M. Sánchez de Diego (coord.), Derecho de acceso a la información pública, Cersa, Madrid, 2008.

SOTO COSTAL, S., El derecho de acceso a la información, Tirant lo Blanch, Valencia, 2011.

TORRES DIAZ, Ma. C., "La fundamentalidad del derecho de acceso a la información pública: análisis crítico desde el marco constitucional de la participación ciudadana", en L. Cotino Hueso, J. L. Sahuquillo y L. Corredoira (eds.), El paradigma del Gobierno Abierto. Retos y Oportunidades de participación y colaboración, Universidad Complutense de Madrid, 2015, pp.115-127. 